\title{
EUGENI D'ORS I LA CONSTRUCCIÓ \\ DEL PROJECTE BIBLIOTECARI \\ DE LA MANCOMUNITAT DE CATALUNYA
}

\author{
TERESA MAÑ̀̀
}

\begin{abstract}
The role of Eugeni d'Ors in relation to libraries in Catalonia has been overshadowed by the weight of the other intellectual contributions of this writer and politician. Ors's role, however, was fundamental in the creation of the Biblioteca de Catalunya; later, thanks to Prat de la Riba, who as president of the Mancomunitat commissioned him to create a library system, Ors designed and planned a library network. He also created the Escola de Bibliotecàries, the first center in Spain of higher education for library professionals. His rationale followed the guidelines of the "free libraries" in Europe and the United States, which Ors knew well and held up in contrast to the antiquated local model. We will discuss the text of the project for the establishment of public libraries to analyze Ors's vision of public libraries as an instrument of cultural regeneration.
\end{abstract}

T a figura i obra d'Eugeni d'Ors és prou coneguda per tots aquells que estudien Uels moviments intel-lectuals del primer terç del segle XX a Catalunya. Amb tot, malgrat que les seves aportacions han estat àmpliament estudiades i que també ho ha estat la seva participació en les propostes culturals de la Mancomunitat, el paper d'Eugeni d'Ors en la implantació de les biblioteques de la Mancomunitat a Catalunya no ha merescut gaire atenció. La biografia i la seva trajectòria professional compten amb una àmplia bibliografia, ja que va ser una figura de pes en el món polític i intel·lectual del primer terç de segle (Quintana i Trias 363-71). Eugeni d'Ors (Barcelona 1881-Vilanova i la Geltrú 1954) va estudiar Dret i, posteriorment, Filosofia i Lletres. De molt jove va col-laborar a la premsa catalana, i l'any 1906 va iniciar a La Veu de Catalunya, la seva obra cabdal, el Glosari, que va publicar fins al 1920. Sota el pseudònim de "Xènius”, Eugeni d'Ors va escriure en aquesta publicació una columna diària on tractava temes d'actualitat artística, política i cultural que va convertir-se en un referent per a tota una generació d'intel-lectuals. Entre els anys 1906 i 1910, Eugeni d'Ors va ser corresponsal de La Veu de Catalunya a París, on havia estat becat per la Diputació de Barcelona per cursar estudis de psicologia i filosofia. L'any 1910 va retornar a Barcelona i, convertit en l'intel-lectual català més popular i influent del moment, va ser nomenat secretari general de l'Institut d'Estudis Catalans (1911). Prat de la Riba, president de la Mancomunitat, delegà en Ors les responsabilitats sobre ensenyament i biblioteques, com a Director 
d'Instrucció Pública. Al 1917, després de la mort de Prat de la Riba, el seu més ferm protector, i la subsegüent substitució en la presidència de la Mancomunitat per Puig i Cadafalch, amb qui mantenia una manifesta incompatibilitat personal, Ors perdé influència gradualment. A començaments de 1920, amb l'excusa d'haver comés una irregularitat administrativa en la gestió de les biblioteques, fou destituït de tots els seus càrrecs. ${ }^{1}$ L'any 1923, Ors es va establir a Madrid, on va viure fins uns anys abans de la seva mort, quan retornà a Catalunya i s'instal-là a Vilanova i la Geltrú. Paradoxalment, allò que el va apartar del país ha resultat ser allò que més ha perdurat de la seva obra de gestió: la xarxa de biblioteques populars.

L'interès de la Mancomunitat i, en concret, de Prat de Riba per la implantació de biblioteques a Catalunya trobà en Ors un excel-lent executor que sabé aprofitar les circumstàncies polítiques favorables per accelerar el procés. La creació de biblioteques públiques forma part del programa de regeneració social i cultural del país que va dur a terme la Mancomunitat; aquesta iniciativa se sumava a altres projectes com la creació de l'Escola del Treball per formar obrers qualificats o l'Escola Especial d'Infermeria per donar oportunitats a les dones. En aquest context se situa la proposta cultural d'Ors de creació de biblioteques i d'una Escola per al personal que se n'havia de fer càrrec (Mañà, Les biblioteques populars de la Mancomunitat). Malgrat els pocs anys que va ocupar-se'n (1915-1920), ja des de l'inici, amb el Projecte per a la seva creació, i després amb la fundació de l'Escola de Bibliotecàries i l'esperit que els inculcà, Ors determinà una manera de fer que perdurà al llarg del temps.

Per comprendre la importància de l'aportació d'Eugeni d'Ors i el canvi que representa en el panorama bibliotecari del primer quart de segle a Catalunya cal veure primer quina era la situació de les biblioteques al país.

\section{LES BIBLIOTEQUES PÚBLIQUES AL TOMBANT DEL S. XX}

Als inicis del segle XX, Barcelona disposava de biblioteques privades però no de biblioteques públiques (o biblioteques populars) a la manera de les "free public libraries" anglosaxones, les biblioteques creades a partir de la segona meitat del segle XIX a Anglaterra i Estats Units i caracteritzades per tenir fons de caràcter general, destinades a tota mena de públic (infants inclosos), amb els llibres de lliure accés als prestatges i amb servei de préstec.

Aquest model de biblioteques públiques anglosaxones era conegut, tant a Espanya com a Catalunya, pels sectors més avançats i inquiets del país. D’aquest interès n'hi ha mostres en discursos d'intel-lectuals i lleis del govern espanyol impulsades per polítics il-lustrats. Podem citar, per exemple, el discurs de López Fabra en la inauguració de l'Ateneu Barcelonés el 1875, en el qual reporta un 
viatge fet a Anglaterra i descriu les "free libraries" que ha pogut visitar amb "un espléndido salón de lectura, provisto de un número extraordinario de periódicos, ilustraciones, revistas de instrucción y recreo, científicas, literarias, artísticas, musicales" (33), en uns locals on "todos tienen las mismas facilidades, todos tienen entrada y uso libre de cuantos libros encierran las bibliotecas" (34).

Barcelona no només comptava amb biblioteques privades: així, tenia la Biblioteca Episcopal del Seminari o a la Biblioteca Universitària, però els seus fons no eren adequats per al conjunt de la població. La Biblioteca Episcopal contenia, essencialment, llibres eclesiàstics i de temes filosòfics destinats a l'estudi dels religiosos. La Biblioteca Universitària contenia fons antics provinents de la desamortització i en gran part especialitzats. Tampoc les condicions de l'espai ni les condicions de treball eren gaire atractives: la biblioteca de la Universitat, ubicada en un espai fred i fosc, amb els llibres guardats al dipòsit o tancats dins d'armaris i atesa per personal preparat per preservar els llibres abans que servir-los al públic, era qualificada de "paorosa nevera" per Gaziel (Torra 46) i segons Pla es tractava d'una "organització ja no arcaica sinó prehistòrica" (297).

La manca de biblioteques en condicions ja havia estat discutida per associacions polítiques i culturals, que havien intentat resoldre el problema. Com comenta Alexandre Galí: "Ja feia prop de tres quarts de segle que el poble havia manifestat el deler incontrastable de llegir pel seu compte i havia començat a crear també pels seus mitjans les seves petites $i$ tan ben intencionades com mal orientades [el subratllat és nostre] biblioteques populars en els seus ateneus i casinos" (9).

D'aquestes biblioteques, és cert, n'existien a bastament, fruit dels moviments socials de l'època. En Lectura i biblioteques populars a Catalunya (1793-1914), el seu estudi sobre les biblioteques adreçades a la classe treballadora abans de la creació de les biblioteques populars de la Mancomunitat (1915), Montserrat Comas n'inventaria més de tres-centes a la ciutat de Barcelona i província, pertanyents a gabinets de lectura, ateneus populars i altres associacions que posaven els llibres a disposició del públic. Com fa notar Galí, encertadament, aquestes biblioteques tenien deficiències en els fons que oferien: disposaven de pocs llibres, no hi havia selecció perquè es fornien de donacions $i$, en els casos que n'hi havia, la tria responia als interessos polítics o religiosos — n'hi havia moltes que depenien de parròquies- de les institucions que sustentaven les biblioteques. A més, no podien oferir gaires serveis, ja que no comptaven amb recursos econòmics per disposar de personal preparat i amb dedicació. En alguns casos, i fruit d'associacions de caràcter burgés i menestral, en sorgiren de més ben dotades com la biblioteca del Centre de Lectura de Reus (1859) o la biblioteca de l'Ateneu Barcelonés (1872), ambdues, però, reservades a l'ús dels seus socis.

Amb tot, existien algunes lloables i meritòries iniciatives de caràcter privat per crear biblioteques obertes al públic que miraven de pal-liar la necessitat de 
lectura i cultura de la població. Seria el cas de la Biblioteca-Museu Balaguer creada a Vilanova i La Geltrú el 1884 pel polític i intel·lectual Victor Balaguer (1824-1901). En aquest cas, la creació de la biblioteca formava part d'un projecte polític més ampli centrat en la recuperació històrica i literària del país. Victor Balaguer va fer construir un edifici de nova planta, que contenia objectes -el museu - i documents - la biblioteca-, un compendi de la cultura amb la intenció de donar a conèixer a qualsevol ciutadà la totalitat del saber i va posar-hi al davant l'impressor Joan Oliva. La creació d'aquesta biblioteca marca una fita important en el panorama bibliotecari però no deixa de ser una proposta aillada i el model de funcionament —amb els llibres tancats en armaris, sense préstec, amb catàlegs impresos- encara és lluny de les biblioteques públiques anglosaxones.

La singularitat també es dóna en el cas de la Biblioteca Arús creada el 1895 a la ciutat de Barcelona per donació de Rossend Arús (1844-1891). Arús, filàntrop i maçó lliurepensador, va encomanar als seus marmessors, Valentí Almirall i Antoni Farnés, que quan morís, convertissin el seu pis i la seva biblioteca personal en una "biblioteca general d'accés lliure" perquè contribuís a la formació de la ciutadania i a la de les classes populars. En els seus estatuts es feia constar que la biblioteca havia de ser pública, havia de tenir tot tipus de llibres i havia d'estar oberta a tot tipus de gent, principis característics de la biblioteca pública. S'inaugurà amb un fons molt ric en nombre (aprox. 26.000 volums) i en temes (més progressista que el fons de les biblioteques populars que crearà la Mancomunitat) però, com altres biblioteques existents a Catalunya - i a l'Estat espanyol - funciona amb sistemes d'organització antiga que no permetien l'accés lliure als prestatges ni el préstec de llibres.

Una altra biblioteca que s'acostuma a citar en la descripció del panorama bibliotecari de l'època és la Biblioteca Popular de la Dona, fundada per Francesca Bonnemaison (1872-1949) al 1909 per dotar d'un instrument de cultura aquelles dones que s'endinsaven en el món laboral de principi de segle: "Tota dona val més, quan lletra aprèn" es llegeix en el rosetó de la sala de lectura. ${ }^{2}$ La biblioteca va ser la primera d'Europa destinada a les dones i, a diferència de les altres esmentades abans, oferia servei de préstec (i comptava per fer-ho amb les necessàries condicions higièniques, com una estufa de desinfecció!). En aquest cas, però, no era pròpiament una biblioteca pública ja que es tractava d'una biblioteca exclusivament femenina i que requeria ser alumna de l'Institut de Cultura per utilitzar-la.

\section{LA FASE PRÈVIA: LES GLOSES}

Tot aquest seguit d'iniciatives privades a finals del segle XIX i principis del XX, amb una clara vocació de posar la cultura a l'abast de la població en general, 
venen motivades per la manca d'iniciatives públiques en aquest sentit. A més de la migradesa de biblioteques públiques, el país mancava també de biblioteques d'estudi, biblioteques per a la investigació, l'absència de les quals impedia, a parer de molts intel-lectuals i polítics, el desenvolupament cultural de Catalunya. Des de 1907, existia l'Institut d'Estudis Catalans, creat per la Diputació de Barcelona, la biblioteca del qual seria l'origen de la Biblioteca de Catalunya que no s'inauguraria fins el 1914. Aquesta biblioteca en els seus inicis, però, no resultava suficient, com manifestava Antoni Rubió i Lluch, president de l'Institut d'Estudis Catalans, en la memòria de l'any de creació de l'entitat: "Penseu, senyor, en la lamentable inferioritat de medis de treball en que es troben els estudiosos de Catalunya, tenint que guanyar-s'ho tot per sí propis, mancats de relació i d'estímul, sense més llibres que els que individualment posseeixen" (Institut d'Estudis Catalans 7).

En aquesta situació, no ens ha d'estranyar el debat generat l'any 1910 a la premsa sobre el model de biblioteca que calia impulsar a la ciutat de Barcelona. Aquesta discussió la van encapçalar Eugeni d'Ors, des de la seva secció Gloses de La Veu de Catalunya, i Lluís de Zulueta, pedagog i polític vinculat al republicanisme catalanista, que havia fet estades d'estudi a París i Berlín i que en aquells moments era regidor de la ciutat de Barcelona. En aquesta polèmica, les biblioteques, tant les d'estudi com les públiques o populars, eren considerades un element imprescindible i així ho manifesten en els seus escrits els qui intervenen en la discussió: les opinions divergeixen sobre quin tipus de biblioteca era prioritari en aquells moments a Catalunya. Eugeni d'Ors es manifesta a favor de la creació d'una biblioteca científica mentre que Zulueta veu més útil i prioritari la creació de biblioteques populars.

Ors inicia el debat en la glosa "Llibres...!" de 13 de juny de 1910 reclamant la compra del fons especialitzat del llibreter Lorentz, una manera de suplir la manca de llibres per als investigadors:

I ara jo penso, ab tot el dolor d'aquest món: ¿Quant han costat a Barcelona les seves últimes i ridícules festes? - ¿No hi hauria fins i tot vantatges econòmics immediates en substituir a l'actual regisme de Badocràcia, de tirania dels badocs, un regisme de cultura? - ¿Trigaran molt en imposar-se aquí els homes qui creuen que, de tot, lo més necessari, LO MES URGENT, és dotar de llibres a una ciutat que no té llibres, una ciutat "a on el treball intel·lectual seriós és impossible" per manca de fonts?...

UNA CIUTAT SENSE LLIBRES! - Jo exilaria sense remordiments, de la nostra república, a qualsevulla català que no sentís de seguida tot l'horror "a on el treball intel-lectual seriós és impossible" per manca de fonts tot l'horror mitgeval! — d'aquests mots... (Ors, Glosari 1910-1911, 184-185)

I poc després a la glosa "El clam" de 14 de juliol de 1910 hi retorna. En ella narra la visita que li fa un dels joves que havien obtingut un pensionat de la 
Diputació de Barcelona ${ }^{3}$-Ors mateix també havia tingut una d'aquestes bequesen tornar d'Alemanya, entusiasmat per la formació rebuda i preocupat pel futur:

$\mathrm{Si}$, però, ¿i després? Quan aquest home preciós, quan els seus companys sien de retorn a Barcelona, ¿com s'ho arreglaran per a continuar les seves tasques? ¿Com els serà possible el treball EN UNA CIUTAT SENSE LLIBRES? [...] RES, res de veritable valor modern podran fer - després d'haver tastat la vida científica i d'haver-se dolorosa, abnegadament capficat per a ells. [...] I una riquesa espiritual admirable s'haurà malgastat. I serà miserablement perduda, perduda, perduda la sembra més esperançadora que mai la Renaixença catalana hagués fet... Un cop més, torni a sonar el clam: LLIBRES...! LLIBRES! (216)

Entre el 17 de setembre i l'1 d'octubre, i arran de la seva estada a Munic i l'experiència d'utilitzar la Biblioteca General i Pública de la ciutat, Ors reprèn la defensa de la biblioteca de llibres per a la investigació en una sèrie de tretze gloses, que aparegueren sota el títol genèric de "Biblioteca". Per a aquesta qüestió, són especialment significatives la primera, de 17 de setembre de 1910, i les tres darreres — "Biblioteca X" de 29 de setembre, "Biblioteca XI. Epíleg" de 30 de setembre i "Biblioteca XII (Apèndix)" d'1 d'octubre. En aquestes gloses escrites durant la seva estada, Ors justifica la prioritat de la creació d'una biblioteca d'investigació abans que una biblioteca popular argumentant que el poble disposa ja de les biblioteques dels ateneus, d'alguna biblioteca pública com ara la Biblioteca Arús i, fins i tot, d'una de provincial per bé que universitària. Segons manifesta en la primera de les gloses d'aquesta sèrie, la del 17 de setembre, "la creació de noves Biblioteques Populars pot ésser útil a Barcelona; no és indispensable ni menys urgenta. Les que existeixen omplen d'una manera acceptable el seu comès" (277).

Segons Ors, no es podia dir que faltessin els llibres bàsics: els que mancaven eren els especialitzats. I, per demostrar quina mena de llibres calen, dedica sis de les gloses (de la 4 a la 9 d'aquesta sèrie) a la transcripció i enumeració de part del catàleg de la Biblioteca de Munic: revistes i llibres de filosofia, psicologia, història natural, física i pedagogia en anglès, alemany i francès, a més dels d'història d'Espanya, dels quals fa notar l'existència de títols en castellà - L.G. de Salazar, Las bienandanzas futuras. Historia general de España; Alzola y Mirando, Las obras públicas en España; J. Ortega, Historia de la Regència de Maria Cristina - i d'adquisició recent com l'obra Documents per a la Historia de la Cultura Catalana Mitgeval de l'Institut d'Estudis Catalans, incorporat al fons de la biblioteca el 1909.

Es interessant fer notar que Ors no es limita a la defensa d'un tipus de fons sinó que, com apunta a la glosa del 29 de setembre, consigna serveis de la biblioteca pública, com el préstec i el préstec entre biblioteques, del tot inexistents a Catalunya i a Espanya i que després incorporarà al seu projecte (el subratllat és nostre): 
Treballo. Tot lo que imagino que pugui ésser-me útil per a guiar-me, per a documentar-me en la feina, aquí és. No tinc que fer sinó demanar-ho. Si vull, un cop la sala hagi tancat, m'ho puc endur a casa. Si tinc dubtes sobre lo que pugui convenir-me, el bibliotecari em guiarà. Si per gran atzar o per la mena especialíssima dels meus estudis, lo que jo desitjo no es trobés aquí, m'ho enviarien d'una altra Biblioteca d'Alemanya i ho tindria qui passat demà. (300)

I l'endemà, en la glosa “Biblioteca XI. Epíleg”, on agraeix a Hermenegildo Giner de los Ríos que hagi firmat la sol-licitud per a la compra del fons Lorentz, aclareix:

Quan jo us dic que no ens calen, que no ens calen amb urgència Biblioteques populars, me refereixo a la qualitat dels llibres, no a les persones cridades a servir-se'n. La Casa de Cultura que necessitem no ha de ser institut de divulgació, sinó científica, però ha de romandre OBERT A TOTS, seguint el gran principi napoleònic - adquisició inesborrable, definitiva, de l'època moderna: LA CARRERA OBERTA ALS TALENTS. (303)

A "Biblioteca XII (Apèndix)", un dia després, Ors comenta la Memòria de l'Institut d'Estudis Catalans i retorna sobre la demanda de llibres de ciències: "Les desfavorides, que cal cuitar a socórrer, són les ciències pures, les ciències filosòfiques, matemàtiques, físiques i naturals... [...] Es necessari que lo que l'Institut ha fet pels estudis històrics, noves institucions ho facin per a altres estudis” (305).

La qüestió de les biblioteques no sembla preocupar més a Ors fins l'any 1914 en què s'inaugura la Biblioteca de Catalunya i a la qual dedica cinc gloses entre els mesos de maig i juny: "Les realisacions" (27 de maig de 1914), "Glosa de l'Institut" (28 de maig de 1914), "L'etapa" (30 de maig de 1914), "Per acompanyar la primera vetlla d'estudi a la biblioteca" (3 de juny de 1914) i "La primera setmana de la Biblioteca de Catalunya" (15 de juny de 1914). En aquests textos es mostra del tot satisfet pel resultat de comptar amb una biblioteca d'aquesta envergadura, amb tan gran nombre de volums i tant èxit de públic com manifesta el 27 de maig: "A tot s'arriba, quan se sap i vol ben treballar. Clamàvem per constituir a Barcelona un centre de viure científic, i ja el tenim. Ploràvem per tant de llibres que no trobàvem, i ja els tenim" (Ors, Glosari 1912-1913-1914 830).

De les biblioteques populars Ors en parlarà per primera vegada en la glosa del 9 de juliol d'aquell any titulada precisament "Biblioteques populars" i dedicada a Francisco Montanyà i Santamaria, diputat per Cervera i Solsona a l'Assemblea de la Mancomunitat. Aquest diputat havia estat el responsable d'una proposta per la implantació de biblioteques populars de la qual derivarà el projecte posterior redactat per Ors. ${ }^{4}$ En aquesta glosa, Ors se centra en un aspecte de les biblioteques que el preocuparà enormement: la constitució del fons. Com bé diu,

[una Biblioteca popular] ha d'ésser, per prèvia definició, educativa; i ho serà tant per allò que conté, com per "allò que no conté". L'establiment de són catàleg només, JA ES 
UN ACTE PEDAGÒGIC. Doncs, en principi, res ha de contenir-se en ella que no sia conscienta voluntàriament escollit. [...] La divisa d'una bona Biblioteca popular ha d'ésser aquesta: “Guerra al donatiu espontani”. (870)

Quan Ors publica aquesta glosa, el Consell d'Investigació Pedagògica del qual forma part ${ }^{5}$ ha rebut ja l'encàrrec de redactar un projecte per a la implantació de Biblioteques i ell en serà l'artífex.

\section{LA REALITZACIÓ: EL PROJECTE}

El projecte que Eugeni d'Ors presenta al Consell Executiu de la Mancomunitat el maig de 1915 és un text breu —unes deu pàgines - en el qual es dissenya el sistema de biblioteques populars de la Mancomunitat, que serà el primer de l'Estat espanyol i l'únic fins als anys vuitanta del segle XX. Fins aleshores tota creació d'una biblioteca havia estat independent de les altres; en canvi, en el Projecte de la Mancomunitat, les biblioteques formen una xarxa de la qual la Biblioteca de Catalunya és el nòdul central amb la qual podran compartir serveis de préstec, adquisicions i models de catalogació uniforme: les biblioteques funcionaran totes de la mateixa manera, sota una sola direcció i això els permetrà, no només créixer de manera homogènia, sinó projectar el missatge de la Mancomunitat que uneix nacionalisme i progrés per tota Catalunya. Aquest missatge nacionalista es farà palès en tots els discursos de colllocació de primeres pedres i d'inauguració d'edificis, tant d'Eugeni d'Ors com d'altres polítics (Mañà, Les biblioteques populars de la Mancomunitat 75-79).

El Projecte conté dotze apartats, nou dels quals dedicats a l'organització i funcionament de la biblioteca i els tres restants dedicats a la formació del personal. En el text Ors senta les bases d'un sistema bibliotecari, que s'organitzarà segons les tècniques modernes de biblioteques, comptarà amb installlacions i edificis propis, disposarà de tot tipus de fons (llibres, revistes, diaris) de lliure accés per a tots els públics (és a dir, incloent-hi infants i dones) i oferirà servei de préstec $\mathrm{i}$ activitats de difusió cultural. Com s'ha comentat anteriorment, les biblioteques públiques que existien tenien sistemes d'organització que no permetien que el públic accedís als llibres: aquests es trobaven al magatzem o tancats en armaris i calia demanar-los per poder-los consultar; a més, l'ordenació no era temàtica sinó per número de registre o per mida amb la qual cosa el lector no podia localitzar la matèria que l'interessava; els llibres no podien sortir de la biblioteca i, evidentment, aquestes biblioteques no disposaven de materials dirigits a públics específics, per exemple, llibres per a infants o revistes de modes o novel-les per al públic femení, perquè no els consideraven un públic potencial. Les biblioteques anglosaxones havien 
posat en marxa noves tècniques d'organització de biblioteques que facilitaven l'accés del públic als llibres: a partir de la Classificació Decimal de Melvin Dewey, ${ }^{6}$ organitzaven les col-leccions de les biblioteques en prestatges oberts de tal manera que tothom pogués buscar i trobar allò que li interessés.

Aquestes mateixes biblioteques preparaven tota mena d'activitats per a la difusió dels fons, com les guies de lectura, xerrades i conferències, a més d'activitats de formació per als escolars. Aquestes biblioteques modernes, pensades més per al públic que per als llibres, són el model de les biblioteques definides en el Projecte. Un model "copiat" dels models estrangers que Ors coneixia tant per les seves estades a l'estranger com per allò que s'havia publicat sobre el tema així com per la Biblioteca de Catalunya que, sota la direcció de Jordi Rubió, havia posat en marxa aquestes innovacions en l'organització (Fontanals 83-127). El model que proposa Ors no és nou, però és innovador en el context en què es presenta.

El Projecte s'inicia amb un apartat en què es justifica que la creació de la Biblioteca de Catalunya hagi estat prèvia a la de les biblioteques populars, ja que aquesta havia de ser la biblioteca cap o biblioteca central de la xarxa. L'any 1910, Ors reclamava la Biblioteca científica; un cop creada, Ors articula un sistema de biblioteques que treballa en xarxa i té la Biblioteca de Catalunya com a central. Així ho manifesta en l'apartat del Projecte titulat Oportunitat del moment per a la creació de Biblioteques Populars:

Quan se tractava en la formació de la que s'ha anomenat Biblioteca de Catalunya i quan, en l'entusiasme per l'idea, sentint vigorosament la dolor i l'angunia pel nostre miserable estat anterior en matèria de llibres, se feia propaganda per aquella, algunes veus impacients s'aixecaren per a demanar que la Biblioteca de Catalunya no tingués el caràcter de dipòsit de llibres de ciència pròpiament dits, sinó més aviat llibres de divulgació de la ciència. Aquestes veus s'inspiraven en la doble creença que, d'una banda, una Biblioteca destinada a estudis científics no tindria en la nostra ciutat un èxit de concorrència i que, d'altra banda, la popularització de la cultura era com una manera de qüestió prèvia que calia resoldre abans d'entrar en accions a favor de la producció científica.

La realitat ha vingut a desmentir rodonament la primera previsió. La Biblioteca de Catalunya és avui un èxit, àdhuc en el més material dels sentits, en el de l'abundor d'assistència. Tot ens indica que amb ella hem satisfet una necessitat real, una necessitat primària, una necessitat urgent. I, quant a la segona part d'aquella creença, bastarà dir que, lluny d'ésser la resolució del problema de Biblioteca de difusió cultural, una qüestió prèvia a la de la Biblioteca d'estudis ja especialitzats i complets, era, al contrari, per ço que anem a dir de seguida, l'institució d'aquesta darrera Biblioteca, un indispensable antecedent a l'acció organitzadora de Biblioteques Populars. ("Projecte" 75-76)

Cal avançar, però, que la relació entre la Biblioteca de Catalunya i les populars, enteses com branques o sucursals de la primera, no es durà a terme fins 
l'establiment de la Direcció Tècnica l'any 1920 amb Rubió al capdavant. ${ }^{7}$ La relació amb la Biblioteca de Catalunya en l'etapa Ors es limitarà al préstec però, pel que fa a l'organització, les populars seran del tot independents.

Altres aportacions pròpies d'Ors diferencien el seu Projecte dels models de referència. Essencialment, aquesta empremta orsiana es manifesta en el disseny i la ubicació de l'edifici, la constitució del fons i la formació del personal.

\subsection{Les instal-lacions: "el començ d'una vida nova"}

La biblioteca que proposa Ors ha de ser una biblioteca que trenqui amb els exemples del passat, tan poc atractius, tan antics, tan poc seductors per al públic. Aquesta qüestió per a Ors és molt important perquè "la instauració del sistema de Biblioteques Populars ha de representar el començ d'una vida nova en els pobles de Catalunya" (80), i això només s'aconseguirà "amb una puresa i amb un allunyament respecte als contactes de la vida vella" (80). Les condicions que ha de complir l'edifici i on s'ha d'ubicar conformen un dels apartats del Projecte en què Ors incideix més. En fer aquesta proposta, Ors no es pot estar de manifestar la seva l'obsessió per fer de la biblioteca un lloc alternatiu al casino i que actuï com a antídot dels mals hàbits:

La nostra oculta ambició fóra, amb una institució així, de produir un canvi, respecte la vida moral dels nostres pobles en el sentit d'arribar al subvertiment d'allò que la realitat d'ells ens dóna avui, en condicions no sempre lloables. En els pobles solem trobar avui un Casino relativament gran, el qual està anex a una biblioteca sempre petita i miserable; el Casino, ultra servir de punt de reunió serveix per a altres fins, gens moralitzadors moltes vegades, i la Biblioteca, d'altra banda, inútil i generalment no concorreguda, o bé convertida en una sala més del Casino, està totalment contaminada de l'ambient d'aquest. Nosaltres, invertint això, voldríem fer, al revés, una Biblioteca que tingués anex un lloc de civil reunió; el qual en aquest cas resultaria envaït i beneficiat de l'ambient de recolliment i de cultura de la Biblioteca. (79-80)

Aquest nou concepte de biblioteca requerirà, sobretot, una nova imatge. En aquest sentit, l'edifici es converteix en la pedra de toc per al bon resultat d'aquest Projecte; les biblioteques s'han d'instal-lar en edificis propis, construits de nou amb aquesta finalitat i han d'oferir una imatge allunyada de sales polsoses i decrèpites:

Res d'instal-lacions vergonyoses i ambigües en recons de Municipis, d'edificis oficials, vells, mig enrunats, polsosos. Res de promiscuïtats amb oficines burocràtiques o amb instituts que no donen gaires senyals de vida. La instauració del sistema de Biblioteques Populars ha de representar el començ d'una vida nova en els pobles de Catalunya, i això ha de produir-se amb una puresa i amb un allunyament respecte als contactes amb la vida vella. $(80)$ 
Aquesta dèria per edificis “propis, independents, nets, blancs, clars, decorats amb higiènica i econòmica coqueteria, i presentant per dins i per fora un aspecte estètic, gai, plaent a l'ull” (80), propiciarà uns espais polits, confortables i agradables per atreure el públic.

Al contrari dels models anglesos i nord-americans que situen les biblioteques en llocs cèntrics, les biblioteques edificades en l'època d'Ors es construiran fora vila, en passejos i camins que portaven sovint a ermites i santuaris: "per poc que sigui possible, serà bo que es presentin isolades, voltades només d'aire i vegetació. Les Biblioteques Populars han d'ésser com a colònies materials i espirituals de l'esperit civil de la modernitat, fins a les més apartades campanyes" (81).

La biblioteca per a Ors pren el caràcter d'un temple de saviesa, un temple de cultura, al qual cal peregrinar en busca del saber. Anys després, però, quan el projecte s'hagi executat aquesta ubicació serà criticada en escrits de les bibliotecàries en considerar que l'accés en dies de fred, pluja o en plena foscor es difícil per al públic i per a elles (Mañà, Les biblioteques populars a Catalunya a través dels seus anuaris 109-10). ${ }^{8}$

\subsection{La tria dels llibres: un acte pedagògic}

"Constituir una biblioteca és un acte pedagògic. El catàleg d'una Biblioteca Popular és un acte pedagògic" ("Projecte” 82). Aquesta afirmació, que ja anunciava Eugeni d'Ors en la glosa “Biblioteques populars" del 9 de juliol de 1914, reapareix en el Projecte i és la base per determinar la colllecció de llibres que es posaran a disposició del públic.

En una biblioteca, per a Ors, tanta importància pren la selecció com el sistema d'adquisicions, el manteniment i l'actualització de la col·lecció. Per això resulta tan significativa la primera de les recomanacions per a l'adquisició: la biblioteca només ha d'acceptar donatius en metàl-lic. Aquest principi és capital per garantir la qualitat del fons de la biblioteca:

L'acceptació de donatius en llibres és una de les causes que tantes biblioteques rudimentàries de Casinos o altres que coneixem, esdevinguin mortes, abandonades, sense cap utilitat. S'hi acumulen publicacions anodines, donatius de particulars o empreses poc generoses o forçats per compromís a la generositat, vils fulletons, opuscles miserables, memòries financeres il-legibles d'empreses, d'entitats oficials, etc., presents d'autors grafòmans, tot el material en fi de cap interès, de lectura impossible o inútil, d'impossibles catalogacions. Tota aquesta escombraria omple els armaris, dificulta la consulta i descoratja alhora el bibliotecari i el lector. La capa de pols va creixent a poc a poc en els prestatges que contenen dipòsits així, tan poc apetitosos de llegir, i en poc temps la Biblioteca resta convertida en una establa d'Augies que solament un nou Herakles podria netejar i ordenar. Una Biblioteca Popular ha d'ésser tot el contrari d'això. Les nostres Biblioteques Populars han d'ésser llamineres a l'apetit de cultura. (82-83) 
Si la funció de la biblioteca és guiar el lector, instruir-lo i formar-lo, la constitució del fons és determinant per acomplir aquesta funció.

Així mateix, el fons de les biblioteques, segons Ors, ha d'atendre a dos tipus de lectors:

a) Al públic mitjà de la localitat, proporcionant-li obres cabdals de tota disciplina, tractats pràctics per a tota activitat, obres de divulgació sobre tot coneixement, informació de la marxa del món i de les idees de fruïció estètica en les obres literàries.

b) A un altre públic més reduït sens dubte, però digne de gran interès, constituït pels homes de professió, de vocació o d'aficions intel·lectuals de la localitat, proporcionant-li instruments de treball indispensables. (77)

Per complir amb les necessitats dels dos tipus de lectors, per als primers existirà el fons general, de caràcter enciclopèdic, de lliure accés i amb servei de préstec; per als segons, s'establirà el préstec amb la Biblioteca de Catalunya que proveirà les obres especialitzades. En l'estructura d'aquest sistema bibliotecari definit en el Projecte, cadascuna de les biblioteques populars constitueix una sucursal de la Biblioteca de Catalunya.

\subsection{Les bibliotecàries: missioneres de la cultura}

Aquesta nova biblioteca que proposa Ors compta, a més, amb un personal preparat específicament per responsabilitzar-se d'ella; en aquest sentit Ors fa una proposta innovadora en projectar una formació especialitzada que no existia en cap dels països de l'entorn: l'Escola de Bibliotecàries, que és el primer centre de formació bibliotecària creat a Europa.

Només els darrers tres apartats del Projecte estan dedicats a la formació del personal i la creació de l'Escola de Bibliotecàries, uns apartats concisos i precisos que determinen com s'han de seleccionar i formar les futures bibliotecàries. "Sobre la natura d'aquest personal havem reflexionat molt" diu Ors abans d'enumerar les condicions que caracteritzaran el personal de les biblioteques, la primera de les quals és que el personal ha d'esser femení.

Aquesta solució, Ors la justifica per una raó econòmica i una altra pedagògica. Econòmica, perquè la decisió d'acceptar només alumnat femení li permetia pagar menys per la mateixa feina ja que les dones rebien sous menors. A la vegada, com que no existia gaire oferta d'estudis professionals per a les dones, fóra molt possible que les que optessin per bibliotecària fossin noies instruïdes i amb estudis previs, com així fou. El fet que per ingressar a l'Escola s'hagués de fer un examen acreditatiu de coneixements generals, d'altres coneixements relatius a Catalunya i de dues llengües modernes, una de les qual era obligatòriament el francès, dóna idea del nivell exigit. La condició femenina del personal permetia disposar de 
millors candidats per més bon preu: "La possibilitat d'obtenir així una relativa reducció de despesa i la seguretat que, a igualtat d'aquesta, així com sol-licitant personal masculí el que acudiria fóra segurament de segon ordre, sol-licitant-lo femení aquest podria ésser de primer ordre i ben triat" (85). Les noies que podien i volien estudiar no tenien en aquells moments gaires possibilitats de formació superior i l'Escola de Bibliotecàries s'insereix perfectament en la línia iniciada pel Consell de Pedagogia a fi de dotar les dones de sortides professionals dignes. L'ingrés a l'Escola fou restringit a alumnat femení des del primers curs, l'any 1915, fins l'any 1976.

La segona raó, la pedagògica, té a veure amb la funció que havien de complir les bibliotecàries i que s’adeia a la seva condició femenina: "el caràcter de missió, d'obra d'educació social que atribuïm a les Biblioteques Populars de Catalunya. En una obra així, la dona és, com sabem tots, un instrument excel·lent” (85).

S'hi afegia també una qüestió estètica ja que el personal femení era el més adient per assegurar "el caràcter atractívol, amable, de netedat i coqueteria que volem donar a les nostres instal-lacions" (86). Cal tenir present el context en què s'escriuen aquestes opinions.

Els estudis d'aquestes professionals integraven una doble preparació: d'una banda, la formació tècnica, en el coneixement i la pràctica de biblioteques; d'altra, una formació " d'humanitats en general, de cultura superior, d'espiritualitat elevada, que faci que puguin considerar-se les persones encarregades d'aquest servei com a veritables missioners [sic] en els pobles, de tota mena de superioritat" (85).

El mateix Ors relata, en el report sobre organització i primera actuació de l'Escola Superior de Bibliotecàries del 15 de gener de 1916, ${ }^{9}$ tres mesos després d'iniciar-se l'activitat acadèmica, algunes de les característiques del personal i de la formació que marcaran la feina i la manera de fer de les bibliotecàries en les seves destinacions. Segons l'informe, les alumnes de bibliotecàries s'ocupaven de manera voluntària de l'ornament de l'Escola i d'alguns dels treballs de neteja; no feien exàmens, seguien les classes de manera "socràtica", assistien a conferències i visitaven biblioteques. Ors en l'informe les anomena "futures missioneres de l'obra de la civilitat a Catalunya". Tenien, a més, una formació sòlida; sabien llengües clàssiques i modernes, tenien coneixements científics i tècnics: havien entrat en una esfera social i intel·lectual superior. Eren, i se sentien, unes escollides.

L'objectiu final d'Ors és que les bibliotecàries siguin un llevat de transformació social i cultural en els seus destins, alhora que donin exemple de les seves creences patriòtiques. Així formula aquesta aspiració en el Projecte:

Imaginem ara una senyoreta que ha rebut la seva educació elemental i l'ha perfeccionada després, i alhora li ha donat un sentit sentimental i patriòtic en alguna institució com l' Institut de Cultura i Biblioteca Popular per a la Dona, o bé en les Institucions que es creïn 
de tendència semblant; que, en arribant la seva joventut i amb vocació de professionalitat entra en la nostra petita Escola de Bibliotecàries; que hi passa tres anys rebent una educació ensems tècnica, selectíssima i patriòtica, i no trencant la seva comunicació amb els centres freqüentats anteriorment, conserva i acreix la maturitat moral ja alcançada i es disposa a persistir en ella i a servir-ne d'exemple i de viva propaganda; que, en arribant als seus vint anys troba situació segura, elevada i ennoblida per una missió social; que s'ha armat d'instruments de cultura fins ara reservats als molt escollits; que s'ha armat alhora d'una competència estricta i d'una elevada cultura. ¿No semblarà lícit que posem en la multiplicació d'un tipus social així alguna esperança de fecunditat en l'obra de transformació de condicions intel-lectuals de la nostra dona i també de la nostra societat en general? ("Projecte” 87-88)

El Projecte d'Eugeni d'Ors preveia també la formació continuada de les bibliotecàries reunint-les un cop l'any a la mateixa Escola de Bibliotecàries amb l'objecte de posar al dia els coneixements. A partir de 1918, un cop incorporada al món laboral la primera promoció de l'Escola, s'iniciaren les Reunions de bibliotecàries que tenien lloc durant les vacances de Nadal. Aquestes reunions eren un espai de trobada per a l'intercanvi i la formació permanent — s'hi debatien qüestions tècniques, s'impartien conferències $\mathrm{i}$ es feien visites a altres centres bibliotecaris i arxius - però, a la vegada, propiciaven el contacte humà entre les professionals que treballaven allunyades les unes de les altres donada la dispersió dels punts de servei. Des de l'any 1918 fins al 1924 se celebra una reunió anual; a partir d'aquest moment s'aturà aquesta activitat que no es reprengué de nou fins l'any 1930.

\section{CONCLUSIONS}

El Projecte de biblioteques s'aprovà el maig de 1915, el juliol es convocà el primer concurs per tal que els ajuntaments sol-licitessin tenir una biblioteca de la Mancomunitat, i el novembre s'inicià el curs a l'Escola de Bibliotecàries. Tres anys després, les primeres titulades prenien possessió de la seva plaça i les autoritats inauguraven les quatre primeres biblioteques que s'havien concedit i construï de planta: Valls, Olot, Sallent i Les Borges Blanques. Aquest projecte, iniciat amb embranzida i també amb recursos, fou fruit de la voluntat política de Prat de la Riba i de la personalitat d'Ors i suposà la implantació a Catalunya - i Espanyadel primer sistema de biblioteques públiques modernes.

Ors, primer director d'aquesta xarxa de biblioteques populars i de l'Escola on es formà el personal que se'n feia càrrec des dels seus inicis al 1915 fins l'any 1920, i després Rubió, que el va substituir sumant aquest càrrec al de Director de la Biblioteca de Catalunya, adapten i repliquen a Catalunya el funcionament i 
l'organització de les biblioteques que coneixen i ho fan amb encert, rigor i eficàcia. L'èxit de l'empresa cal vincular-lo, no només a una meticulosa planificació i una direcció capacitada, sinó també a un personal degudament preparat i entregat. Aquest sistema creat al 1915 ha estat la base de l'actual sistema de biblioteques de Catalunya que complirà ben aviat el seu primer centenari.

TERESA MAÑ̀̀

Universitat de Barcelona

\section{NOTES}

1 La dimissió d'Ors tingué lloc el 8 gener de 1920 després d'una intensa discussió a l'Assemblea de la Mancomunitat en què se l'acusà d'una mala pràctica administrativa com a responsable de biblioteques, basada en irregularitats detectades en les despeses sol-licitades per a la biblioteca de Canet acabada d'inaugurar el 8 de desembre de 1919. La Direcció de Biblioteques Populars havia gaudit des dels inicis d'una certa llibertat perquè pogués fer lliurement les despeses i justificar-les després, tal com s'havia fet en les anteriors inauguracions de Valls, Sallent, les Borges Blanques i Olot (totes inaugurades el 1918). A més, el període en el qual s'inaugurà Canet era extraordinàriament mogut des del punt de vista social i calia usar sistemes que requerien una flexibilitat administrativa que no s'adeia amb les normes burocràtiques de la Mancomunitat. Una altra acusació es recull en l'expedient del cas: la disposició segons la qual les Biblioteques Populars farien festa el dia 15 de novembre, dia de Sant Eugeni. El fet que la circular en què es decreten els dies festius de les biblioteques porti data del 14 de setembre de 1918, any i mig abans dels fets que se l'acusaven, demostra la banalitat d'alguns dels arguments esgrimits per a la defenestració. Bofill i Mates va ser particularment incisiu en el procés per part, com han recollit estudis recents (Fuentes 152-53).

2 La frase és l'inici d'una cançó satírica de Cerverí de Girona que fou utilitzada fora de context ja que aquest no era el sentit que li donava el trobador.

3 Enric Prat de la Riba, com a president de la Diputació de Barcelona, havia instituiit al 1907 beques per realitzar estades d'estudis a l'estranger, en paral·lel a les beques creades per la Junta para Ampliación de Estudios de Madrid.

4 La proposta de Montanyà fou feta per la Comissió de Govern a l'Assemblea de la Mancomunitat el 26 de maig de 1914 i aprovada amb algunes modificacions. Les modificacions proposaven que la creació de biblioteques fos supeditada a la sol-licitud dels Ajuntaments en vista de les ofertes que fessin i que les obres fossin a càrrec d'ells; l'elecció dels fons seria responsabilitat de l'Institut d'Educació General. L'Assemblea aprovà el dictamen de la Comissió tres dies després, en l'acta del 29 de maig. A continuació, el 17 de juny, el Consell Permanent sol-licità un projecte al Consell d'Investigació Pedagògica que contemplés els següents aspectes: llista de llibres, organització dels serveis, instal·lació, obligacions del municipi i variants en la tipologia de biblioteques en relació als habitants.

5 El Consell d'Investigació Pedagògica de la Mancomunitat fou una comissió creada el 1914 per a l'assessorament pedagògic i desenvolupament dels ensenyaments. Eugeni d'Ors en formà part com a vocal responsable d'Ensenyança Superior, Acadèmies i Biblioteques. 
6 La Classificació Decimal Dewey és un sistema de classificació bibliogràfica que divideix les disciplines del coneixement humà en deu classes. Rep el nom de Melvil Dewey, bibliotecari nordamericà, que el desenvolupà el 1876.

7 Jordi Rubió i Ors, director de la Biblioteca de Catalunya, assumí el 17 de març de 1920, en substitució d'Ors, la Direcció Tècnica de les Biblioteques Populars i la Direcció de l'Escola de Bibliotecàries. Una de les seves primeres accions fou posar en marxa la Central Tècnica de Biblioteques amb la funció de donar suport tècnic a les biblioteques i vetllar per al manteniment de la unitat de mètodes i serveis en totes elles.

8 Al Diari de la Biblioteca d'Olot, el 16 de maig de 1925, es pot llegir el comentari que fa una futura bibliotecària en pràctiques: "La biblioteca és una mica allunyada de la població perquè la gent la freqüenti, com segurament ho faria si fos més al cor de la població”. Un comentari semblant trobem en una carta de la bibliotecària de Valls a Jordi Rubió de l'1 de desembre de 1923, dipositada a l'arxiu de la Biblioteca, on escriu que es podria fer una conferència a la nit, "si la biblioteca no estés tan apartada de la ciutat".

9 Document consultat a l'Arxiu de la Biblioteca de Catalunya, capsa 500, carpeta Servei de Biblioteques-organització (1915-1939). En el moment de la consulta (2005) no existia un inventari complet ni exhaustiu de tots els documents continguts en aquest lligall.

\section{REFERÈNCIES}

Comas, Montserrat. Lectura i biblioteques populars a Catalunya (1793-1914). Barcelona: Curial, 2001.

Fontanals, Reis i Marga Losantos. Biblioteca de Catalunya, 100 anys: 1907-2007. Barcelona: Biblioteca de Catalunya, 2007.

Fuentes, Maximiliano. "La defenestració de Xènius: una qüestió política i ideològica". Cercles. Revista d'Història Cultural. 15 (2012): 137-64

Galí, Alexandre. "Biblioteques populars i moviment literari”. Història de les institucions $i$ del moviment cultural a Catalunya. Vol. XI. Barcelona: Fundació Alexandre Galí, 1984.

Institut d'Estudis Catalans. Memòria presentada per l'Institut d'Estudis Catalans al Excm. Sr. Alcalde de Barcelona i llegida en Consistori del dia 13 de novembre de 1907. Barcelona: La Neotípia [1907].

López Fabra, Francesc. "Breves apuntes sobre las bibliotecas públicas y gratuitas de Inglaterra, su institución y su objeto”. Actas del Ateneo Barcelonés 29 de novembre de 1875. Barcelona: Tip. de Narciso Ramírez y Cia., 1876.

Mañà, Teresa. Les biblioteques populars de la Mancomunitat de Catalunya 1915-1925. Lleida: Pagés, 2005.

- Les biblioteques populars a Catalunya a través dels seus anuaris 1922-1936. Barcelona: Facultat de Biblioteconomia i Documentació-Universitat de Barcelona-Diputació de Barcelona, 2001.

Ors, Eugeni d’. Glosari 1910-1911. Edició i presentació de Xavier Pla; anotació de Jordi Albertí. Barcelona: Quaderns Crema, 2003.

-. Glosari 1912-1913-1914: amb la sèrie "Flos Sophorum”. Edició, presentació i notes de Xavier Pla. Barcelona: Quaderns Crema, 2005. 
Pla, Josep. “Eugeni d'Ors (1882-1954)". Homenots: primera sèrie. Barcelona: Destino, 1969.

"Projecte d'acord presentat a l'Assemblea de la Mancomunitat en la tercera reunió, celebrada el 26 de maig, de 1915, sobre la instal-lació a Catalunya d'un sistema de biblioteques populars”. Anuari de les biblioteques populars 1922. Barcelona: Consell de Pedagogia. Direcció Tècnica de Biblioteques Populars [1923]: 75-89. També publicat a: Butlletí de la Biblioteca de Catalunya 2 (1915): 122-33.

Quintana Trias, Lluís. "Eugeni d'Ors”. Panorama crític de la literatura catalana. Segle XX. Del Modernisme a l'avantguarda. Ed. Enric Bou. Vol. V. Barcelona: Vicens Vives, 2010. 363-71.

Torra, Jordi i Pilar Llopart. La Biblioteca de la Universitat de Barcelona. Barcelona: Publicacions Universitat de Barcelona, 1994. 